\title{
Framing Climate Uncertainty: Frame Choices Reveal and Influence Climate Change Beliefs
}

\author{
ASTRID KAUSE \\ Centre for Decision Research, University of Leeds, Leeds, United Kingdom, and Harding Center for Risk Literacy, \\ Max Planck Institute for Human Development, Berlin, Germany \\ TARLISE TOWNSEND \\ Department of Health Management and Policy, University of Michigan School of Public Health, Ann Arbor, Michigan

\section{WOLFGANG GAISSMAIER} \\ Harding Center for Risk Literacy, Max Planck Institute for Human Development, Berlin, and \\ Department of Psychology, University of Konstanz, Konstanz, Germany
}

(Manuscript received 8 January 2018, in final form 3 November 2018)

\begin{abstract}
The public debate around climate change is increasingly polarized. At the same time, the scientific consensus about the causes and consequences of climate change is strong. This inconsistency poses challenges for mitigation and adaptation efforts. The translation of uncertain numerical climate projections into simpler but ambiguous verbal frames may contribute to this polarization. In two experimental studies, we investigated 1) how "communicators" verbally frame a confidence interval regarding projected change in winter precipitation due to climate change $(N=512)$ and 2) how "listeners" interpret these verbal frames $(N=385)$. Both studies were preregistered at the Open Science Framework. Communicators who perceived the change as more severe chose a concerned rather than an unconcerned verbal frame. Furthermore, communicators' verbal frames were associated with their more general beliefs, like political affiliation and environmental values. Listeners exposed to the concerned frame perceived climate change-induced precipitation change to be more severe than those receiving the unconcerned frame. These results are in line with two pilot studies ( $N=298$ and $N=393$, respectively). Underlying general beliefs about climate and the environment likely shape public communication about climate in subtle ways, and thus verbal framing by the media, policymakers, and peers may contribute to public polarization on climate change.
\end{abstract}

\section{Introduction}

Public polarization on climate change has intensified over the past decade. This has been especially severe in the United States, limiting climate change mitigation efforts by one of the world's largest emitters of greenhouse gases (Dunlap et al. 2016). Other Western developed countries face an analogous but less marked schism (McCright et al. 2016; Hornsey et al. 2016). The way in which climate change information is communicated to the public may contribute to these divides (Brüggemann and Engesser 2017; Mossler et al. 2017; Pidgeon and Fischhoff 2011). A particular challenge for climate change communicators is to communicate the

Corresponding author: Astrid Kause, a.kause@leeds.ac.uk uncertainty inherent in climate projections (Budescu et al. 2012, 2014). Uncertain projections are often summarized in ambiguous ways. For example, numeric projections are translated into verbal expressions (e.g., replacing "more than $90 \%$ chance" with "very likely"). Such expressions are interpreted inconsistently across individuals (Budescu et al. 2014; Visschers et al. 2009) and contexts (Beyth-Marom 1982). These interpretations may be associated with individuals' underlying beliefs and perceptions related to climate change (Budescu et al. 2014) and may vary according to the strength of their prior beliefs (Benjamin et al. 2017). We examined whether "communicators" who perceive climate change impacts to be more severe are more likely to select verbal frames that emphasize their severity concern, and whether "listeners" exposed to such a frame highlighting 
its severity in turn interpret such climate consequences to be more severe.

\section{a. Verbal frames for summarizing numerical information}

The same numerical information can be framed in a variety of ways (Cacciatore et al. 2016; Scheufele and Iyengar 2014). "Framing effects" most famously refer to the phenomenon in which logically equivalent statements (i.e., each statement necessarily entails the other) that describe the same numerical information are informationally nonequivalent, such that the choice of frame influences the listener's conclusions (Sher and McKenzie 2006).

Seminal research in decision sciences illustrates that preferences in a choice task depend on whether the alternatives are framed as gains or losses. For instance, a surgery with an $80 \%$ survival rate is perceived as more acceptable than one associated with a $20 \%$ mortality rate. When the two represent the same numbers but expressed as certain versus uncertain, participants prefer the safe option when the task is framed as a gain ("800 people saved") and the risky option when it is framed as a loss (" $20 \%$ probability of 1000 people dying"). In other words, individuals' willingness to accept risk is dependent on how the decision alternatives are verbally framed (Tversky and Kahneman 1981).

Frame choices might implicitly leak information and reveal a communicator's underlying beliefs (McKenzie and Nelson 2003; Tversky and Kahneman 1981). In health decisions, this may be the surgeon's underlying preference regarding their patient's treatment, when the same statistical outcome is expressed in different numerical formats (Marteau 1989; McNeil et al. 1982; Wilson et al. 1987) or different verbal frames (Mandel 2014). In turn, a listener's interpretation of two logically equivalent but informationally distinct statements is likely to match these underlying cognitions (Sher and McKenzie 2006; Chong and Druckman 2007). Morton et al. (2011) demonstrated a related effect in the context of climate change: in the face of uncertainty about the consequences of climate change, participants were more willing to behave pro-environmentally when exposed to a gain frame compared to a loss frame (see also Scannell and Gifford 2013; Spence and Pidgeon 2010).

While psychological research on framing effects has typically examined statements that are logically equivalent (Sher and McKenzie 2006), framing has also been defined more broadly in the sense of which elements are selected or emphasized (Nelson et al. 1997). Indeed, framing used in everyday parlance (Cacciatore et al. 2016) may often fail to satisfy the strict definition of logical equivalence, raising questions about the choice and effects of such frames. In the context of climate change communication, we believe that frames that summarize the same numeric information but are logically nonequivalent are of particular relevance, and we will describe them subsequently.

\section{b. Verbal frames summarizing uncertainty in climate communications}

In the academic literature, projections and related uncertainties are often presented in the form of a mean estimate and two confidence interval bounds, a format rarely found in communication by the media, policymakers, or other public figures. Rather, such information may be summarized verbally, often via verbal frames like "as much as," "not more than," or "as little as." For example, an article in The Guardian, describing results from the Intergovernmental Panel on Climate Change (IPCC) Fourth Assessment Report, stated that "across Africa, yields from rain-fed agriculture could decline by as much as $50 \%$ by $2020 "$ (Clarke 2012; IPCC 2014; see appendix $\mathrm{H})$. In climate communications, different verbal frames of the same confidence interval bound may imply different likelihoods of reaching this bound, and subtly express how severe the communicator perceives the event to be. The concerned frame "could decline by as much as 50\%" may imply higher concern and could, in turn, lead those who receive this statement to perceive climate change consequences as more severe. Conversely, the same results could have been verbally framed in a less concerned manner by saying that the "decline is very unlikely to be greater than $50 \%$." The latter frame could thus result in lower levels of perceived severity in recipients.

Furthermore, such communication often omits one side of the interval ("one-sided uncertainty interval"; Teigen 2008). The emphasized side of the uncertainty interval may reflect the underlying "provisional reference point," drawing the listener's attention to that same point. The language used to describe the reference point, in turn, reflects the individual's beliefs about the outcome and the directionality of a statement (Teigen 2008): "More than $X$ " implies that a projection is likely larger than the reference point, whereas "less than $X$ " implies that it is smaller.

Listeners' interpretations of such statements may then be influenced by verbal frames, along with their own underlying beliefs and perceptions related to climate change (Smithson et al. 2012; Teigen et al. 2007). Similarly, the various verbal frames used in climate communication to the public (see appendix $\mathrm{H}$ for further examples). For example, "as much as $X$," may emphasize how extreme the outcome could be. Conversely, phrasings such as "unlikely to be more than $X$ "—as in the above example from The Guardian, and as used by 
the UK's Met Office to communicate climate change projections-may downplay the size of the outcome, though they refer to the same numeric bound. Additionally, expressions such as "unlikely" may further draw attention toward a less severe outcome. These frames are logically nonequivalent: "as much as $X$ " does not necessarily entail "unlikely to be more than $X$." Yet they are alternative summaries of the same numeric informationthe upper bound of an uncertainty interval. Thus, while verbal frames of confidence intervals in climate change communications may be easier to understand than numbers, they provide room for selecting and presenting information in line with communicators' prior beliefs ("preference-based reinforcement"; see Cacciatore et al. 2016).

For studying framing effects in climate communication, we adopt a broader definition of these (Cacciatore et al. 2016). Climate information is often framed differently by different communicators, but these different framings rarely fulfill the strict definition of being logically equivalent. Rather, they often represent different ways of summarizing the same numerical information, such as quantitative scientific statements about climate projections (appendix H). Understanding what these frame choices reveal about communicators and how they influence listeners seems crucial to understanding their contribution to polarization. In this study, we thus examine a set of verbal frames that, while not logically equivalent, are used in everyday communications to summarize uncertain numeric estimates from climate research-and which may both reflect the communicator's beliefs and influence the listener's.

\section{c. Underlying beliefs affect climate risk perceptions}

Perceptions of climate change are associated with political affiliation. For example, Dunlap et al. (2016) report a 33-47-point difference in the percentage of Democrats versus Republicans who believed that climate change is occurring, anthropogenic, and serious; that there is scientific consensus on climate change; and that the seriousness of climate change is exaggerated in the media. Furthermore, political affiliation influences the interpretation of climate change information (Carmichael et al. 2017; Hart et al. 2015). For instance, Malka et al. (2009) showed that increasing knowledge about the scientific findings regarding climate change increased concern among Democrats and Independents but not among Republicans. This relationship was moderated by trust in scientists and mediated by perceptions that climate change is anthropogenic as well as by perceived scientific agreement about a changing climate. "Motivated reasoning," in which individuals interpret information in ways that reinforce their prior beliefs, may explain these results (Hart and Nisbet 2012; Hart et al. 2015). Similar to political affiliation, environmental values are associated with skepticism about climate change (Poortinga et al. 2011; Whitmarsh 2011).

\section{d. Research question and hypotheses}

Despite the ubiquity of confidence-interval communication in the context of climate change, the process of selecting verbal frames for describing interval bounds is not well understood. We investigate whether so-called communicators who perceive climate change impacts to be more severe, and who care about environmental issues more generally, are more likely to choose a verbal frame that may emphasize greater concern when describing the upper confidence interval bound of a climate change projection (study 1). In line with prior findings on framing effects, we predict that the selected frame will be associated with levels of perceived severity of an event (prediction 1). Furthermore, we investigate whether so-called listeners who receive a frame that may be expressing higher rather than lower concern for describing this bound, in turn, expect the event to be more severe (study 2). We predict that their perceptions of the projected change will be influenced by the verbal frame used for communicating the confidence interval bound (prediction 2). We selected two frames that are commonly used to communicate climate change projections, although they were not logically equivalent (and thus our study differs from other studies on framing effects in this respect). In both studies, we include assessments of political affiliation as well as environmental values, levels of numeracy, and levels of education. We anticipate an interaction between the participants' political affiliation and the frame to which they were exposed in study 2 : specifically, we predict that participants who identify as Democrats will be more influenced by the more concerned frame than those who identify as Republicans (prediction 3).

We preregistered both studies on the Open Science Framework. Study materials and power analyses were based on two pilot studies conducted in $2013(N=298$ and $N=393$, respectively; see https://osf.io/3tr4h/). Results of these studies provided initial support for the aforementioned hypotheses. To allow the reader to assess replicability, we report pilot results in appendixes B-F. Datasets from the main studies are also available at http://review.researchdata.leeds.ac.uk/512/.

\section{Study 1}

Study 1 assessed whether participants selected verbal frames for describing an uncertain climate projection in 
TABLE 1. Sample characteristics of study 1 and study 2, compared to excluded participants in each study. In each study sample, participants were excluded because they did not complete questionnaires, did not answer the attention check correctly, or because we could not categorize them on the political affiliation scale, based on their open-ended answer. When comparing the remaining communicators to those excluded, no statistical difference occurred with regard to any of the used measures (all $p$ values $>0.6$ ). Excluded listeners did not differ in any of the other measures (all $p>0.3$ ).

\begin{tabular}{|c|c|c|c|c|}
\hline & \multicolumn{2}{|c|}{ Study 1} & \multicolumn{2}{|c|}{ Study 2} \\
\hline & $\begin{array}{l}\text { Final sample } \\
\qquad(N=512)\end{array}$ & $\begin{array}{l}\text { Excluded } \\
\text { participants }\end{array}$ & $\begin{array}{l}\text { Final sample } \\
\qquad(N=385)\end{array}$ & $\begin{array}{l}\text { Excluded } \\
\text { participants }\end{array}$ \\
\hline$M_{\text {age }}$ (years) & $\begin{array}{c}36.23(\mathrm{SD}=11.25 \\
\quad \text { range }=19-77)\end{array}$ & $38.67(13)$ & $\begin{array}{l}37.22(\mathrm{SD}=12.43 \\
\quad \text { range }=19-79)\end{array}$ & $37.75(13.3)$ \\
\hline Percentage male & 57 & $\begin{array}{l}27 \\
\text { Missing: } 56\end{array}$ & 55 & $\begin{array}{l}20 \\
\text { Missing: } 45\end{array}$ \\
\hline Levels of education (\%) & $\begin{array}{l}\text { High school or } \\
\text { lower: } 13 \\
\text { College: } 78 \\
\text { Graduate school: } 9\end{array}$ & $\begin{array}{l}\text { High school or } \\
\text { lower: } 12 \\
\text { College: } 39 \\
\text { Graduate degree: } 6 \\
\text { Missing: } 44 \%\end{array}$ & $\begin{array}{l}\text { High school or } \\
\text { lower: } 12 \\
\text { College: } 73 \\
\text { Graduate school: } 15\end{array}$ & $\begin{array}{l}\text { High school or } \\
\text { lower: } 9 \\
\text { College: } 41 \\
\text { Graduate school: } 6 \\
\text { Missing: } 45\end{array}$ \\
\hline$M_{\text {Political_affiliation }}(\mathrm{SD})$ & $3.39(1.92)$ & $3.42(2.09)$ & $3.50(1.92)$ & $2.79(1.89)$ \\
\hline$M_{\text {Environmental_values }}(\mathrm{SD})$ & $3.69(0.77)$ & $3.64(0.70)$ & $3.67(0.82)$ & $3.77(0.62)$ \\
\hline$M_{\text {Numeracy }}(\mathrm{SD})$ & $2.31(1.24)$ & $2.13(1.19)$ & $2.35(1.19)$ & $2(1.12)$ \\
\hline
\end{tabular}

line with their underlying levels of perceived severity of climate change consequences.

\section{a. Materials and methods}

\section{1) PARTICIPANTS}

We recruited an online convenience sample from the general U.S. population via Amazon Mechanical Turk. In advance of study 1 , we conducted a power analysis for linear logistic regression, based on the pilot data. To detect an effect similar to the odds ratio of at least 1.44 observed in the pilot for the main independent variable, a sample of $N=509$ participants was required. To account for attrition, we increased this number to $N=$ 598 participants. We excluded participants who did not finish the questionnaire, answered "other" or "do not know" on the political affiliation scale and did not give an open-ended answer that would allow us to recategorize them, or did not answer an attention check question correctly. This resulted in an overall $N=512$. The average study duration was $M_{\text {communicators }}=7.48 \mathrm{~min}$ [standard deviation $(\mathrm{SD})=5.81$ ]. Table 1 provides a sample description and results of statistical comparisons between the final sample and excluded participants.

\section{2) Procedure And Measures}

Communicators received a brief explanation of why climate projections can be uncertain. They were then told that Greater London may experience heavier winter precipitation due to climate change. They learned that there was an 8 out of 10 chance that the change in winter precipitation will be somewhere between an increase of $3 \%$ and an increase of $33 \%$, with the most likely change being an increase of $15 \%$. A graph adapted from the Met Office's 2009 United Kingdom Climate Projections 2009 report (UKCP09) aimed to improve understanding of this information (Fig. 1). We chose this scenario because most American participants are broadly familiar with London but lack extensive direct experience with the city's climate, limiting the effect of prior knowledge and experience on their responses.

They were then asked to imagine explaining this projection to a friend deciding whether to vote for floodresilient infrastructure in the city that would require considerable government spending. To do so, participants chose one of two verbal frames summarizing the projection, likely reflecting different levels of concern (Table 2; appendix A). We selected the unconcerned verbal frame "very unlikely to have increased more than..." from the most recent set of climate projections for the United Kingdom (Murphy et al. 2010), where it is used to describe outcomes at the $10 \%$ and $90 \%$ interval bounds. The concerned counterpart, "could have increased by as much as," was selected because the "as much as" formulation is commonly used to summarize numeric projections in climate change communications to the public (see appendix $\mathrm{H}$ ).

After selecting one of the framed statements, we measured participants' perceptions related to severity of climate change consequences: A five-item scale included one general assessment of perceived severity and four questions concerned with more specific types of outcomes, based on the 2010 Draft Climate Change Adaptation Strategy for London (Greater London Authority 2010; Table 2). Responses across all five items were combined into a single perceived severity scale (Cronbach's $\alpha=0.90$ ). 


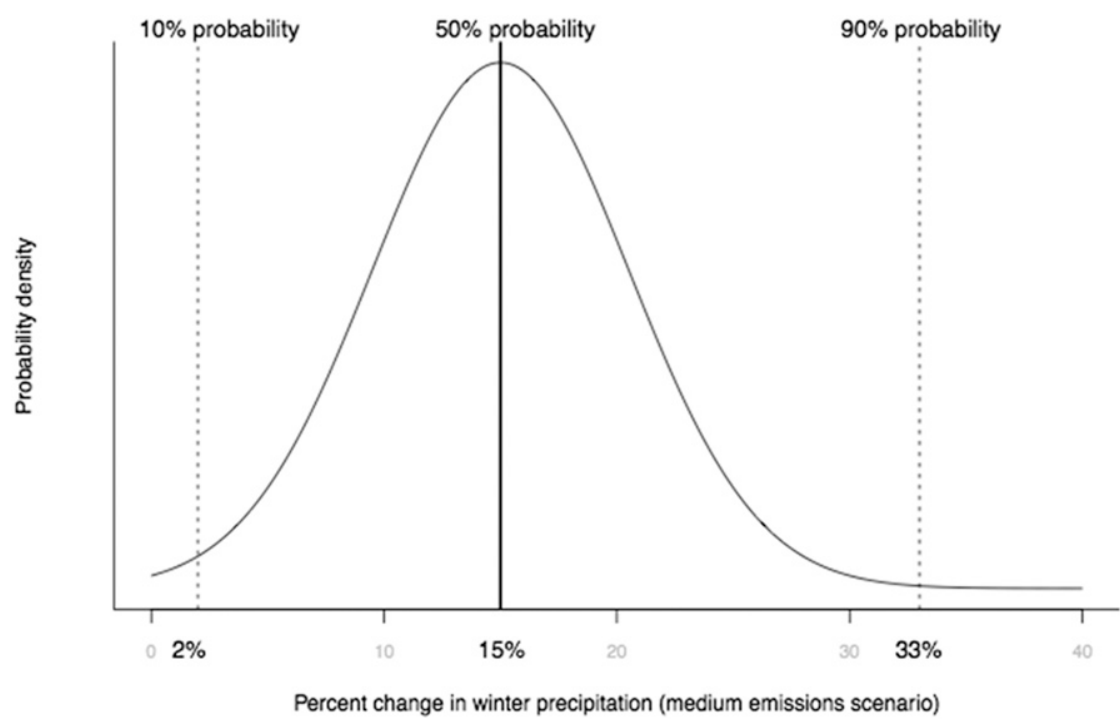

FIG. 1. Graphical display of the climate change projection used in both study 1 (communicators) and study 2 (listeners), with accompanying text. The percentage displayed on the $x$ axis is equivalent to the amount of precipitation change. The area under the curve represents the likelihoods or probabilities associated with different amounts of precipitation change. The vertical lines indicate which amount of precipitation change is associated with the $10 \%, 50 \%$, and $90 \%$ probability levels of the probability density function. Participants received the following description: "The graph above makes predictions very similar to those made by the UKCP09. It suggests that there is an 8 out of 10 chance that the change in winter precipitation will be somewhere between: an increase of 2 percent and an increase of 33 percent. This is represented by the area between the dashed lines. The central estimate is an increase in 15 percent, which corresponds to the highest point in the curve. Changes that correspond to lower points on the curve are less likely to occur. The probability that the change in precipitation will be less than 2 percent or higher than 33 percent is 2 out of 10 . This corresponds to the area below and above the dashed lines."

Environmental values were assessed via the 15 -item New Ecological Paradigm scale (NEP; Dunlap et al. 2000) where each item is rated on a scale from 1 ("strongly agree") to 5 ("strongly disagree"). For example, participants were asked to rate statements such as "When humans interfere with nature it often produces disastrous consequences" and "Despite our special abilities humans are still subject to the laws of nature." Participants' average answer across 15 items was $M=3.31$ (SD $=0.33$ ). Cronbach's $\alpha=0.91$ indicated sufficient internal reliability of the NEP scale and was slightly higher than the validation sample ( $\alpha=$ 0.83; Dunlap et al. 2000). Political affiliation was assessed on a seven-point scale ranging from 1 ("strong Democrat") through a midpoint of 4 ("independent") to 7 ("strong Republican"), as well as two additional categories "do not know" and "other." Based on their explanations in an open-ended text field, participants who indicated "other" were recategorized on the Democrat-Republican spectrum (see Table 1; overall $M=3.38, \mathrm{SD}=1.92)$. Numeracy was assessed with the adaptive version of the Berlin Numeracy Test (BNT;
Cokely et al. 2012; see also Kahan et al. 2012; Hart 2013). The average numeracy score was $M=2.31(\mathrm{SD}=1.24)$, which is slightly lower than in the validation sample $\left(M=2.60, \mathrm{SD}=1.13\right.$; Cokely et al. 2012). ${ }^{1}$ The BNT was followed by an attention check ensuring that participants carefully read instructions; asking "Do you like to do puzzles? This is an attention check, please answer C) Other" including answer categories A-C. Demographic measures included age, gender (male, female, other), and education (some schooling only, high school diploma or GED, some college, college degree, some graduate school, graduate degree); see Table 1.

Results were analyzed in R, using the function $\operatorname{glm}($ ) in the "stats" package. Dominance analysis (Budescu 1993; Azen and Traxel 2009) was conducted to rank the importance of the predictors. Following LeBreton et al. (2013) interaction terms were residualized. The Health

\footnotetext{
${ }^{1}$ Numeracy scores were distributed as follows. $1: 38 \% ; 2: 21 \%$; $3: 14 \% ; 4: 28 \%$, where 1 indicates very low numeracy and 4 very high levels of numeracy. See also Cokely et al. (2012).
} 
TABLE 2. Items used in both study 1 (communicators) and study 2 (listeners). The projection for precipitation change due to climate change was retrieved from Murphy et al. (2010).

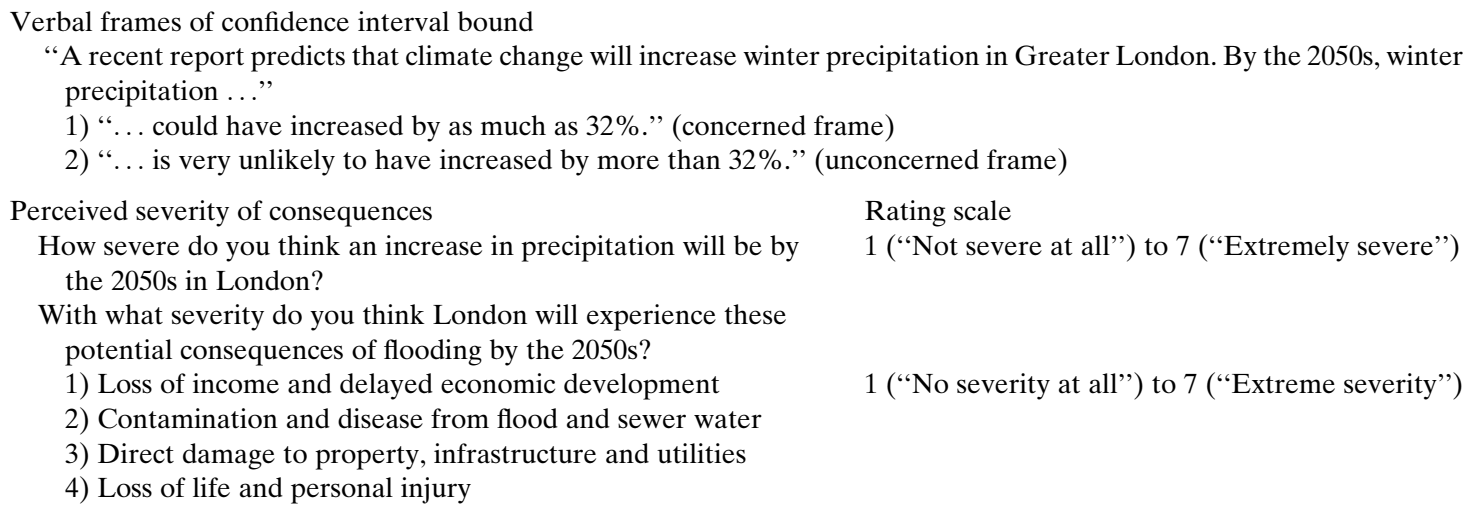

Rating scale

1 ("Not severe at all") to 7 ("Extremely severe")

1 ("No severity at all") to 7 ("Extreme severity")

Sciences and Behavioral Sciences Institutional Review Board at the second author's institution approved both studies.

\section{b. Results}

Choices of verbal frames for summarizing uncertain climate projections are associated with communicators' underlying perceived severity of climate change: Communicators who perceived the consequences of precipitation change to be more severe were more likely to choose the concerned frame $(N=375)$ than the unconcerned frame $(N=137$; Fig. 2a). This was in line with our first prediction, and held when controlling for other predictors and covariates in the logistic regression (Table 3). Choice of the concerned frame was further associated with a more democratic political affiliation ${ }^{2}$ and rather weakly with environmental values. Participants with lower levels of numeracy perceived consequences as more severe and were also somewhat more likely to choose a concerned frame (Table 3 ). Dominance analysis (Azen and Traxel 2009) was used for assessing relative importance of severity, compared to other predictors. Perceived severity generally dominated all other predictors, accounting for $49 \%$ of the model's overall fit. Political affiliation was the second most important predictor, accounting for $30 \%$ of overall fit (appendix D).

A logistic regression model additionally including demographics produced similar patterns. It further indicated that communicators were more likely to choose the concerned frame if they were male $(b=0.55$ [0.23],

\footnotetext{
${ }^{2}$ The model from the main study but not of the pilot study further indicated a three-way interaction between environmental values, political affiliation, and levels of numeracy. As these results were not interpretable and did not replicate findings from the pilot study, we do not provide descriptive statistics here but report those in appendix G.
}

$p=0.02)$, if they perceived consequences as severe and additionally were low in numeracy (severity $\times$ numeracy: $b=-0.36$ [0.14], $p=0.01$ ), or if they additionally had high pro-environmental values (severity $\times$ NEP: $b=0.32$ [0.14], $p=0.02)$. Including demographics slightly decreased model fit. This was indicated by the Bayesian information criterion (BIC), which penalizes additional predictors. The BIC increased from 615 to 652 . To ensure the results were robust to the inclusion of all participants, we predicted perceived severity using similar models and the full dataset $(N=$ 598). This revealed similar patterns. Pilot results are described in appendixes $\mathrm{C}, \mathrm{D}$, and $\mathrm{F}$.

\section{Study 2}

Study 2 assessed whether two different verbal frames for describing an uncertain climate projection influenced listeners' underlying levels of perceived severity of climate change consequences.

\section{a. Material and methods}

\section{1) PARTICIPANTS}

Similar to study 1 , the online convenience sample was drawn from the general U.S. population and recruited via Amazon Mechanical Turk. We conducted a power analysis for linear regression, based on the pilot data. To detect a small effect of $f^{2}=0.05$ for our main predictor (Cohen 1988), a sample of $N=382$ participants was required. To account for attrition, $N=456$ participants were invited to participate. We excluded participants who did not finish the questionnaire, participants who answered "other" or "do not know" on the political affiliation scale and did not give an open-ended answer that would allow us to recategorize them on this scale, and participants who did not answer an attention check question correctly (similar to study 1 ). The final sample 
(a) Study 1: communicators

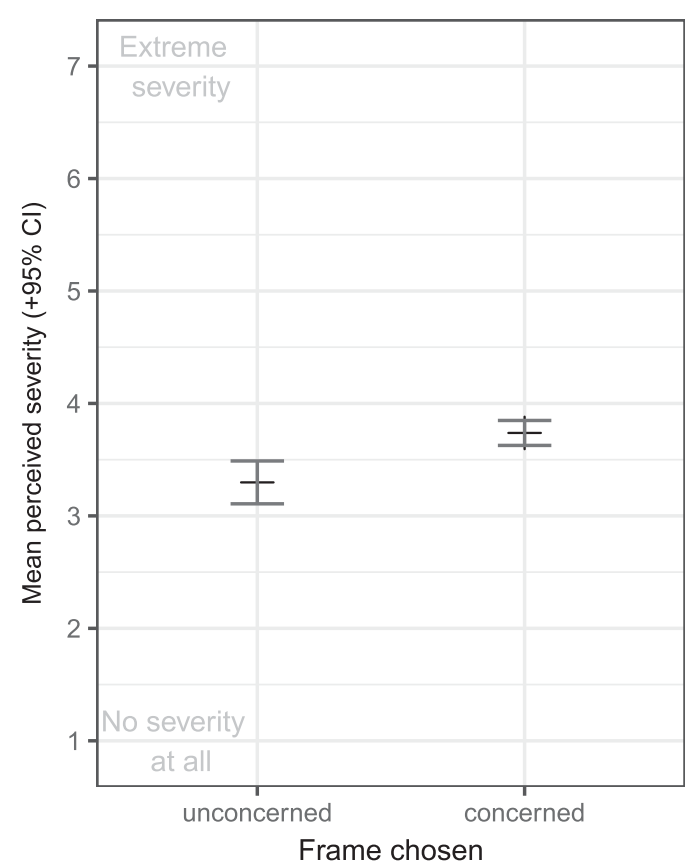

(b) Study 2: listeners

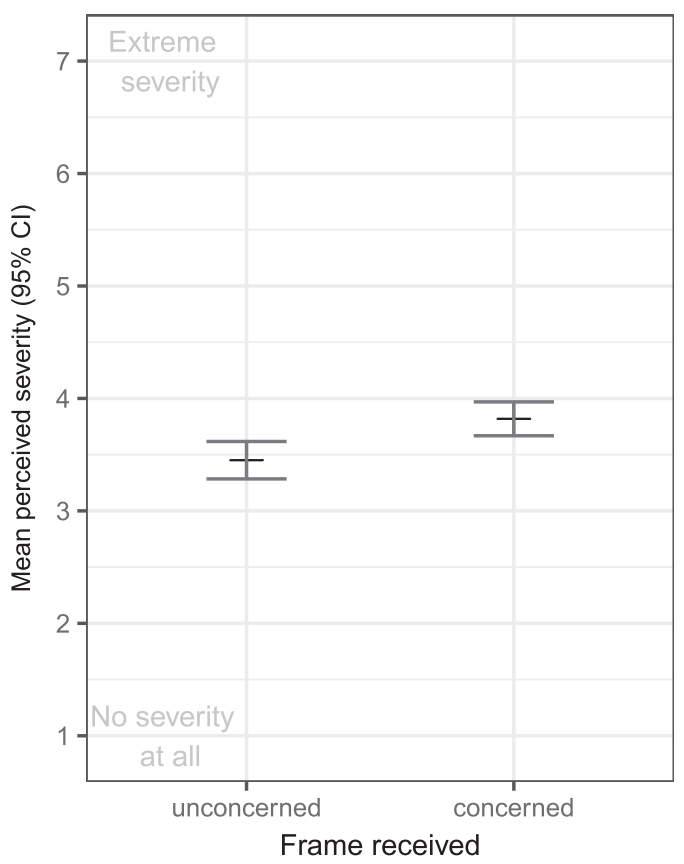

FIG. 2. Mean perceived severity of consequences of precipitation change ( $+95 \%$ confidence interval) by (a) communicators choosing the frame for summarizing an uncertain climate projection in study 1 and (b) listeners, receiving different frames for the uncertain climate projection in study 2 . See Table 2 for the five-item scale used for measuring perceived severity of precipitation change.

included $N=385$ participants. The average study duration was $M_{\text {listeners }}=7.17 \mathrm{~min}(\mathrm{SD}=4.69)$. Sample characteristics are described in Table 1, including statistical comparisons to excluded participants.

\section{2) Procedure and measures}

The introductory text was similar to study 1 . A total of $N=204$ participants received a statement from a London assembly member summarizing evidence from a reputable source on projected changes in winter precipitation. The statement was equivalent to the concerned frame of the uncertain projection in Table 2. A total of $N=181$ participants received a statement equivalent to the unconcerned frame in Table 2 (appendix A). Participants were randomly allocated to experimental groups.

After receiving one of the framed statements, participants were asked to rate the severity of consequences of

TABLE 3. Logistic regression, predicting frame choice (concerned vs unconcerned) in study 1 (communicators). [Notes: BIC $=615$. We categorized participants by reducing political affiliation to a one-dimensional seven-point left to right scale by placing those who indicated "do not know" in the middle of the scale (i.e., 4), by placing those who indicated in the "other" category to vote green, socialist, or communist on the left end of the scale (i.e., 1), and by placing those who indicated to vote constitutional, libertarian, or anarchocapitalist on the right end of the scale (i.e., 7). BIC (full model with all interactions and demographics) $=652$.]

\begin{tabular}{lcrr}
\hline \hline & Coefficient & Standard error & Wald statistic \\
\hline Intercept & 1.04 & 0.11 & 9.14 \\
Perceived severity & 0.27 & 0.12 & 2.23 \\
Political affiliation & -0.26 & 0.12 & -2.27 \\
Environmental values (NEP) & 0.25 & 0.14 & 0.01 \\
Numeracy & 0.13 & 0.12 & 0.03 \\
Perceived severity $\times$ numeracy & -0.21 & 0.12 & 0.08 \\
Political affiliation $\times$ NEP & -0.07 & 0.12 & -1.73 \\
Political affiliation $\times$ numeracy & -0.16 & 0.12 & -0.62 \\
Environmental values $\times$ numeracy & 0.10 & 0.13 & -1.31 \\
Political affiliation $\times$ NEP $\times$ numeracy & 0.26 & 0.12 & 0.77 \\
\hline
\end{tabular}


precipitation change on a five-item scale similar to study 1 (Table 2). Responses across all five items were combined into a single perceived-severity scale (Cronbach's $\alpha=0.92$ ). Listeners were also asked to make a percentage estimate about change via the following question: "What percent change in annual winter precipitation would you expect in Greater London in the 2050s, in comparison with the previous decades?" (see also Teigen et al. 2007). The measures assessing proenvironmental values $(M=3.68, \mathrm{SD}=0.82$; Cronbach's $\left.\alpha_{\mathrm{NEP}}=0.92\right)$, political affiliation $(M=3.50, \mathrm{SD}=1.92)$, numeracy $(M=2.35, \mathrm{SD}=1.19),{ }^{3}$ demographics, and attention check were adopted from study 1 . Answers on perceived severity items and quantitative estimates were analyzed in $\mathrm{R}$, using the function $\operatorname{lm}()$ in the "stats" package.

\section{b. Results}

Verbal framing of an uncertain interval bound influences listeners' perceptions of the projected change: In line with the prediction and pilot results, listeners exposed to the concerned verbal frame perceived the consequences of precipitation change to be more severe than those exposed to an unconcerned frame (Fig. 2b). Further, higher environmental values predicted greater perceived severity, whereas higher numeracy was associated with lower perceived severity. Perceived severity was also higher among participants who had both high environmental values and high numeracy (frame received $\times$ NEP $\times$ numeracy; Table 4 ). A full model including all interactions and demographic variables as main effects produced similar result patterns but resulted in poorer fit to the data. This was indicated by the BIC, which increased from 1074 to 1081. Findings were robust when including all participants $(N=456)$. Further, results were similar to pilot results (appendixes $\mathrm{E}$ and $\mathrm{F}$ ).

Similarly in line with results of the pilot study, the numeric estimate of the percentage precipitation change in listeners was not affected by the verbal frame received (average predictions in each group: $M_{\text {concerned_frame }}=$ 29.37, SD $=13.43$, and $M_{\text {unconcerned_frame }}=27.91, \mathrm{SD}=$ 10.71; see Table 5). We predicted numerical estimates with a linear regression model, similar to the model applied to perceived severity of consequences. Participants tended to make higher estimates when they were

\footnotetext{
${ }^{3}$ Numeracy scores were distributed as follows. $1: 38 \% ; 2: 24 \%$; 3: $17 \%$; $4: 26 \%$, wehre 1 indicates very low numeracy and 4 very high levels of numeracy. See Cokely et al. (2012) for categorization of participants according to answers in the adaptive version of the Berlin Numeracy Test.
}

low in numeracy. A regression model including demographic variables showed a similar pattern and additionally indicated that older $[b=-0.20(0.05), p=$ $0.01]$ and more highly educated participants $[b=-0.10$ (0.05), $p=0.04]$ made lower estimates.

\section{General discussion}

When participants were asked to communicate an uncertain projection on precipitation change due to climate change, they selected a verbal frame that matched their perceptions of the severity of future climate change consequences (study 1). Listeners exposed to a concerned rather than unconcerned verbal frame for the same projection in turn perceived the consequences of precipitation change to be more severe (study 2). These findings align with a set of pilot studies conducted in 2013, and suggest that phrases commonly used to frame numerical information from climate sciences may reveal and influence individuals' perceptions of climate change consequences. Importantly, the alignment between underlying beliefs and selected frame does not imply that it is exactly the prior beliefs we assessed that caused frame selection, but merely demonstrates that frame choices and these beliefs are correlated. Our results also suggest that how verbal summaries of numerical confidence intervals are framed can influence perceptions. These framing effects of the logically nonequivalent frames studied here are similar to more traditional framing effects of logically equivalent frames. These results are important because, in everyday language, framing extends beyond the clean, logically equivalent frames previously investigated in the literature.

To assess the role of more general underlying beliefs about climate change independent of personal experiences, the scenario employed here focused on Greater London. This likely reduced the probability that U.S.-based participants themselves experienced climate change consequences affecting the area. Experience of climate change consequences has been shown to affect perceptions and beliefs of climate change (Bruine de Bruin et al. 2014) and may thus shape perceptions of frames. For example, previous research suggests that framing effects in the context of climate change may depend on how "close" participants perceive the impact to be (Spence and Pidgeon 2010; Scannell and Gifford 2013; McDonald et al. 2015), although this may not always lead to more accurate risk perceptions and adaptive behaviors (McDonald et al. 2015).

We found that political affiliation predicted frame choice in study 1 . This is in line with previous studies that found associations between political affiliation and 
TABLE 4. Linear regression, predicting perceived severity of consequences, dependent on frame received, environmental values, political affiliation, and levels of numeracy in study 2 (listeners). [Notes: BIC $=1074 ; R^{2}$ (adj.) $=0.24$. See Table 3 in study 1 for the recategorization procedure of participants who indicated "do not know" or "other" on the political affiliation scale. BIC (full model with demographics $)=1081 ; R^{2}$ (adj.) $=0.20$.]

\begin{tabular}{|c|c|c|c|c|}
\hline & Coefficient & Standard error & $t$ value & $p$ \\
\hline Intercept & -0.20 & 0.07 & -2.74 & 0.01 \\
\hline Frame received & 0.33 & 0.09 & 3.35 & $<0.01$ \\
\hline Political affiliation & -0.02 & 0.05 & -0.31 & $>0.25$ \\
\hline Environmental values (NEP) & 0.45 & 0.05 & 6.12 & $<0.01$ \\
\hline Numeracy & -0.21 & 0.07 & -2.93 & $<0.01$ \\
\hline Frame received $\times$ political affiliation & 0.01 & 0.10 & 0.14 & 0.89 \\
\hline Frame received $\times$ NEP & -0.07 & 0.10 & -0.71 & $>0.25$ \\
\hline Frame received $\times$ numeracy & -0.04 & 0.10 & -0.43 & $>0.25$ \\
\hline Political affiliation $\times$ NEP & -0.05 & 0.06 & -0.84 & $>0.25$ \\
\hline Political affiliation $\times$ numeracy & 0.02 & 0.08 & 0.19 & $>0.25$ \\
\hline $\mathrm{NEP} \times$ numeracy & 0.01 & 0.08 & 0.06 & $>0.25$ \\
\hline Frame received $\times$ political affiliation $\times$ NEP & 0.03 & 0.09 & 0.38 & $>0.25$ \\
\hline Frame received $\times \mathrm{NEP} \times$ numeracy & 0.21 & 0.10 & 1.97 & 0.05 \\
\hline Frame received $\times$ political affiliation $\times$ numeracy & -0.01 & 0.10 & -0.12 & $>0.25$ \\
\hline Political affiliation $\times$ NEP $\times$ numeracy & -0.01 & 0.07 & -0.20 & $>0.25$ \\
\hline Frame received $\times$ political affiliation $\times \mathrm{NEP} \times$ numeracy & -0.09 & 0.09 & -1.00 & $>0.25$ \\
\hline
\end{tabular}

belief in and perceived risk of climate change (Dunlap et al. 2016; Hornsey et al. 2016). Pro-environmental values were only weakly associated with frame choice, while previous work suggested a relationship between this measure and beliefs about climate change. However, the regression model included perceived severity, which is strongly correlated with pro-environmental values $(r=0.49 ; p<0.01)$, which might explain this disparity.

In study 2, environmental values were associated with perceived severity of precipitation change among listeners.
This is in line with literature indicating relationships among values, political affiliation, and climate change risk perceptions [see Corner et al. (2014) for a summary]. We did not observe an interaction between frame received and political affiliation, which might have indicated that the concerned frame might have influenced perceptions of Democrats more than those of Republicans. Higher numeracy did not reduce the impact of frames in study 2 . In other words, the highly numerate were equally likely to express perceptions of severity that were in line with the verbal frames to which they were exposed. In previous

TABLE 5. Linear regression, predicting quantitative estimates of precipitation change, dependent on frame received, environmental values (NEP), political affiliation and levels of numeracy in study 2 (listeners). [Notes: BIC $=1146 ; R^{2}$ (adj.) $=0.10$. See Table 3 in study 1 for the recategorization procedure of participants who indicated "do not know" or "other" on the political affiliation scale. BIC (full model with demographics) $=1147 ; R^{2}(\operatorname{adj})=$.0.11 .]

\begin{tabular}{|c|c|c|c|c|}
\hline & Coefficient & Standard error & $t$ value & $p$ \\
\hline Intercept & -0.01 & 0.08 & -0.15 & $>0.25$ \\
\hline Frame received & 0.07 & 0.11 & 0.64 & $>0.25$ \\
\hline Environmental values (NEP) & 0.13 & 0.08 & 1.61 & 0.11 \\
\hline Political affiliation & -0.07 & 0.08 & -0.84 & $>0.25$ \\
\hline Numeracy & -0.22 & 0.08 & -2.75 & 0.01 \\
\hline Frame received $\times$ NEP & -0.03 & 0.11 & -0.29 & $>0.25$ \\
\hline Frame received $\times$ political affiliation & 0.08 & 0.11 & -0.67 & $>0.25$ \\
\hline Frame received $\times$ numeracy & -0.03 & 0.11 & -0.26 & $>.25$ \\
\hline Political affiliation $\times$ NEP & 0.08 & 0.07 & 1.21 & 0.23 \\
\hline Political affiliation $\times$ numeracy & 0.07 & 0.08 & 0.79 & $>0.25$ \\
\hline $\mathrm{NEP} \times$ numeracy & 0.06 & 0.09 & 0.74 & $>0.25$ \\
\hline Frame received $\times$ NEP $\times$ political affiliation & -0.03 & 0.09 & -0.31 & $>0.25$ \\
\hline Frame received $\times$ NEP $\times$ numeracy & 0.08 & 0.11 & 0.70 & $>0.25$ \\
\hline Frame received $\times$ political affiliation $\times$ numeracy & -0.05 & 0.11 & -0.48 & $>0.25$ \\
\hline $\mathrm{NEP} \times$ political affiliation $\times$ numeracy & 0.01 & 0.07 & 0.20 & $>0.25$ \\
\hline Frame received $\times \mathrm{NEP} \times$ political affiliation $\times$ numeracy & -0.09 & 0.10 & -0.90 & $>0.25$ \\
\hline
\end{tabular}


research, Peters et al. (2006) showed a relationship between framing effects and numeracy. In that study, however, the frames were logically equivalent, whereas in ours they were not. This makes sense, as we would not necessarily expect for numeracy to "protect" against framing effects when the expressions are not logically equivalent. It may further indicate that, while logically nonequivalent frames of the same numerical information may influence listeners with varying numeracy levels in the usual way, numeracy may no longer be a moderator of these framing effects. Yet interestingly, in study 1 , the highly numerate generally perceived the consequences of increased precipitation to be less severe.

While the verbal frames influenced perceived severity in study 2, quantitative estimates of changes in precipitation due to climate change did not differ between experimental conditions. This also held true for pilot study 2 and was the case even though these quantitative estimates were moderately correlated with perceived severity. This result differs from prior research showing that the directionality of verbal frames affects numeric estimates (Budescu et al. 2003; Teigen et al. 2007; Hohle and Teigen 2018). Future research should thus investigate the way in which perceptions measured more qualitatively (e.g., perceived severity of climate change impacts, as used in the present research) are related to more quantitative estimates (precise projections of the impact), and how each in turn shapes support for climate change mitigation and adaptation policy.

In everyday conversations, the type and strength of frames used might vary. When summarizing a climate projection, individuals might choose other verbal frames than the ones studied here and specified in, for example, the UKCP09 outlet (Murphy et al. 2010; see appendix H). Asking participants in an open-ended task to summarize a projection in their own words would enable assessment of the variability and strength of verbal frames used for climate change impacts in conversations and public media outlets. Their choices will likely be associated with their underlying beliefs about climate change.

Furthermore, verbal probabilities may serve other functions in social interaction than the ones described. Communicators, when choosing a verbal frame expressing higher concern, might adhere to listeners' preferences for "worst case" scenarios (Teigen et al. 2007). More generally, omitting numbers in climate projections might indicate less responsibility when the projection turns out to be wrong ("fuzzy cover hypothesis"; Erev and Cohen 1990) but still leave room for expressing underlying beliefs. Listeners, in turn, may perceive a verbal probability statement as a way of protecting either the communicator or the listener from a too-strong statement that may be less well received but less frequent for simply expressing a likelihood ("face management"; Juanchich et al. 2012).

\section{Conclusions}

Different verbal frames used in climate communications may reveal and influence how individuals perceive climate change consequences. This suggests that these verbal summaries of numeric information are neither neutrally chosen nor neutrally interpreted (Scheufele 2014). As a result, verbal framing of uncertain projections (e.g., by the media, online blogs, policymakers, and peers) likely reveals and influences public perceptions of climate change, contributing to polarization on the issue: initially very subtle verbal nuances in climate change communications express different levels of perceived severity. Those levels might be amplified and reinforced when propagated through chains of individuals, in particular when they share a similar viewpoint (Moussaïd et al. 2015). This limits our ability to achieve a basic level of agreement on scientific facts, and it could continue to preclude necessary mitigation and adaptation behaviors.

Our results, together with previous work on communications of climate information, motivate several recommendations for facilitating a more neutral communication of uncertain intervals around climate change projections. One is to accompany verbally described probability levels with their numerical equivalents (Budescu et al. 2014). This decreases variability in how verbally described probability levels are interpreted and likely also the influence of different verbal frames. Furthermore, simple graphical formats may enhance understanding (Galesic et al. 2016; Garcia-Retamero and Cokely 2014; Joslyn et al. 2013; Stephens et al. 2012). These should reflect cognitive design principles that enhance ease of understanding of graphs (Harold et al. 2017). Empirical studies need to assess how well climate information in different numerical and graphical formats is understood by different target audiences (Galesic et al. 2016; Harold et al. 2017). Such strategies could produce a more accurate picture of projected changes and associated uncertainties if they are understandable and simple enough to resonate with beliefs of both listeners and communicators. Ideally, this allows for a better informed and more neutral debate about complex and uncertain scientific issues such as climate change.

Acknowledgments. We thank Mirta Galesic and Wändi Bruine de Bruin for feedback on study results. We also thank David Spiegelhalter who inspired this 
study in an armchair conversation, telling one of the authors (WG) that the media react with much more interest if he states that some consequence of climate change "could be as high as..." than when he states that the same difference "is unlikely to be greater than...," which are exactly the two verbal frames for the upper end of a confidence interval that we used in the study, and also is why we studied them in the first place.

Participants' names were not collected. Each participant was associated with a Mechanical Turk "Worker ID," which was used only for participant compensation and to ensure participant uniqueness. Worker IDs were unlinked from survey data. The authors declare no conflicts of interest with respect to the authorship or the publication of this article.

\section{APPENDIX A}

\section{Study Materials as Used in Study 1 and Study 2}

Thank you for participating in our study!

In this study, we examine how people think about the effects of climate change on first-world countries. For this purpose you will complete several simple calculations, and interpret information presented in graphs and short statements in the way that makes most sense to you. Your data will be collected completely anonymously using an online survey service. The researchers, Amazon Mechanical Turk, and the online survey service will have no way of linking your data with your personal identity.

The Max Planck Institute for Human Development and the University of Konstanz are institutions that promotes scientific research. Our work adheres strictly to regulations governing protection of privacy. The information requested in the study will be kept confidential and archived and scientifically processed in accordance with the Data Privacy Act. Personal data will not be passed on to any third parties. The data will be used solely for research purposes and solely within or in cooperation with both institutions. Personal contact data and experimental data will be stored separately from each other and handled with utmost discretion. Participation in the study is voluntary and you are able to end your participation at any time. You can revoke your consent to use your data at any time from that date forward.

The study will last approximately $20 \mathrm{~min}$. You will be paid $\$ 2$ for completing the study. If you leave the study prior to completion, you will not receive payment.

I have read and accept the terms and conditions listed above and consent to participate in this study (prerequisite for participating in the study)

$$
\text { [] Yes }
$$

\section{[COMMUNICATORS]}

Please read the following information carefully before moving on to the questions.

When thinking about what climate change means for people, one question is how it will affect towns and cities. Governments, businesses, individuals, and other groups can use this information to devise plans for the future development of their community. For example, if severe hurricanes are likely to occur more frequently near a particular coastal city, that community might prepare by building better levees, improving its evacuation plan, and so on.

The 2009 UK Climate Projections (UKCP09) use available climate data to make predictions about the effects of climate change on Great Britain.

Because no one knows exactly how policies, technologies, individual behaviors, and other factors will change

TABLE B1. Sample characteristics of pilot study 1 and pilot study 2. In each subsample, participants were excluded because they either did not complete questionnaires or because in advance of our studies, they participated in pilot studies and were thus too familiar with the experimental materials. In a next step, we excluded those who indicated "don't know" or "other" on the political affiliation scale. When comparing remaining to excluded communicators (pilot study 1 ), no statistical difference occurred with regard to age $[t(30)=0.04, p=1]$. The overall level of education was lower $[t(40)=-3, p=0.01]$. With regard to measures used, they expressed slightly lower environmental values $[t(30)=-2, p=0.05]$ but did not differ on any of the other measures (all $p>0.3$ ). When comparing excluded listeners to remaining listeners (pilot study 2), no statistical difference occurred with regard to age $[t(20)=0.5, p=0.06]$. The overall level of education was lower $[t(100)=$ $-10, p<0.01$ ]. With regard to measures used, excluded listeners did not differ in any of the other measures used (all $p>0.1$ ).

\begin{tabular}{|c|c|c|c|c|}
\hline & \multicolumn{2}{|c|}{ Study 1: Communicators } & \multicolumn{2}{|c|}{ Study 2: Listeners } \\
\hline & Final sample $(N=298)$ & Excluded participants & Final sample $(N=393)$ & Excluded participants \\
\hline$M_{\text {age }}($ years $)$ & $33.3(\mathrm{SD}=11)$ & $33.4(\mathrm{SD}=11.1)$ & $32.5(\mathrm{SD}=10.3)$ & $33.05(\mathrm{SD}=9.23)$ \\
\hline Percentage male & 61 & 57 & 58 & 57 \\
\hline \multirow[t]{3}{*}{ Levels of education (\%) } & High school or lower: 14 & High school or lower: 3 & High school or lower: 13 & High school or lower: 8 \\
\hline & College: 73 & College: 22 & College: 76 & College: 8 \\
\hline & Graduate school: 13 & Graduate school: 2 & Graduate school: 11 & Graduate school: 5 \\
\hline$M_{\text {Environmental_values }}(\mathrm{SD})$ & $3.26(0.70)$ & $3.24(0.69)$ & $3.51(0.66)$ & $2.19(1.21)$ \\
\hline$M_{\text {Political_affiliation }}(\mathrm{SD})$ & $3.12(1.67)$ & $2.07(1.52)$ & $3.20(1.60)$ & $2.00(1.38)$ \\
\hline$M_{\text {Numeracy }}(\mathrm{SD})$ & $2.28(1.17)$ & $2.22(1.05)$ & $2.43(1.16)$ & $2.19(1.21)$ \\
\hline
\end{tabular}


TABLE C1. Logistic regression, predicting frame choice (unconcerned vs concerned) in pilot study 1 (communicators). Notes: BIC $=$ 358. A dominance analysis indicated that perceived severity dominated all other predictors, accounting for $30 \%$ of the model's overall fit (see appendix D). Pro-environmental values were the second most important predictor, accounting for $17 \%$ of overall fit. For the pilot data, we ran the same logistic regression on a larger sample, including communicators, who, when asked about their political affiliation, indicated the category "don't know" or "other." In this larger sample, $N=21$ participants (7\%) did so. We categorized these participants by reducing political affiliation to a one-dimensional seven-point left-right scale by placing those who indicated "do not know" in the middle of the scale (i.e., 4), by placing those who indicated in the "other" category to vote green, socialist, or communist on the left end of the scale (i.e., 1), and by placing those who indicated to vote constitutional, libertarian, or anarcho-capitalist on the right end of the scale (i.e., 7). Including those participants in all reported analyses did not alter displayed results. BIC (full model with all interactions and demographics) $=399$.

\begin{tabular}{|c|c|c|c|c|}
\hline & Coefficient & Standard error & Wald statistic & $p$ \\
\hline Intercept & 1.23 & 0.15 & 8.29 & $<0.01$ \\
\hline Perceived severity & 0.36 & 0.16 & 2.33 & 0.02 \\
\hline Political affiliation & -0.13 & 0.15 & -0.84 & $>0.25$ \\
\hline Environmental values (NEP) & 0.30 & 0.16 & 1.80 & 0.07 \\
\hline Numeracy & 0.18 & 0.15 & 1.16 & 0.25 \\
\hline Perceived severity $\times$ numeracy & -0.10 & 0.15 & -0.73 & 0.47 \\
\hline Political affiliation $\times$ NEP & -0.04 & 0.16 & -0.27 & $>0.25$ \\
\hline Political affiliation $\times$ numeracy & 0.14 & 0.16 & 0.85 & $>.25$ \\
\hline Political affiliation $\times$ NEP $\times$ numeracy & -0.26 & 0.18 & -1.48 & 0.14 \\
\hline Environmental values $\times$ numeracy & -0.09 & 0.16 & -0.55 & $>.25$ \\
\hline
\end{tabular}

in the coming decades, because some aspects of the climate system are incompletely understood and because natural variability occurs in the climate system, there is some uncertainty in these projections.

Consider the graph below as an example very similar to predictions by the UKCP09. It suggests that by the 2050 s, the amount of winter precipitation in Greater London is likely to have increased in comparison to a historical baseline-but by exactly how much it will increase cannot be known beforehand.

Heavier and more frequent winter rainfall events could lead to flooding, which could result in injuries and fatalities, damage to property and infrastructure, disease spread, delayed economic development, and other consequences.

The following statements put the above chart into words. Imagine that you are explaining the prediction to a friend. Your friend, who lives in London, is deciding whether to vote for city infrastructure that is more resilient to flooding. This would help the city adapt to the effects of climate change, but would require significant government spending. Which statement would you choose?

"A recent report predicts that because of climate change, winter precipitation will increase in Greater London. Compared to a historical baseline, by the 2050s, winter precipitation

a. Could have increased by as much as $33 \%$."

b. Is very unlikely to have increased by more than $33 \%$."

\section{[Measures-COMMUNICATORS]}

With what severity do you think London will experience these potential consequences of flooding by the 2050s? (For each, a 7-point scale, ranging from "No severity at all" to "Extreme severity".)

TABLE D1. Dominance analysis results for logistic regression predictors in main and pilot study 1.

\begin{tabular}{|c|c|c|c|c|c|c|}
\hline \multirow[b]{2}{*}{ Predictor } & \multicolumn{3}{|c|}{ Main study 1} & \multicolumn{3}{|c|}{ Pilot study 1} \\
\hline & Dominance & $\begin{array}{l}\text { Standardized } \\
\text { dominance }\end{array}$ & Rank & Dominance & $\begin{array}{l}\text { Standardized } \\
\text { dominance }\end{array}$ & Rank \\
\hline Perceived severity & 0.03 & 0.49 & 1 & 0.02 & 0.30 & 1 \\
\hline Political affiliation & 0.02 & 0.30 & 5 & 0.004 & 0.06 & 2 \\
\hline Environmental values (NEP) & 0.0009 & 0.02 & 2 & 0.01 & 0.17 & 8 \\
\hline Numeracy & 0.0004 & 0.01 & 7 & 0.01 & 0.12 & 4 \\
\hline Perceived severity $\times$ numeracy & 0.002 & 0.03 & 4 & 0.01 & 0.06 & 7 \\
\hline Political affiliation $\times \mathrm{NEP}$ & 0.0001 & 0.002 & 8 & 0.0004 & 0.01 & 9 \\
\hline Political affiliation $\times$ numeracy & 0.001 & 0.14 & 6 & 0.01 & 0.08 & 6 \\
\hline Environmental values $\times$ numeracy & 0.0007 & 0.01 & 3 & 0.01 & 0.06 & 5 \\
\hline Political affiliation $\times$ NEP $\mathrm{x}$ numeracy & 0.0001 & 0.001 & 9 & 0.01 & 0.14 & 3 \\
\hline
\end{tabular}


TABLE E1. Linear regression, predicting perceived severity of consequences, dependent on frame received, environmental values (NEP), political affiliation, and levels of numeracy in pilot study 2 (listeners). Notes: BIC $=1123$. We ran the same linear regression on a larger sample, including communicators, who, when asked about their political affiliation, indicated the category "don't know" or "other." In this larger sample, $N=14$ participants $(3.4 \%)$ did so. We categorized these participants by reducing political affiliation to a one-dimensional seven-point left-to-right scale by placing those who indicated "do not know" in the middle of the scale (i.e., 4), by placing those who indicated in the "other" category to vote green, socialist, or communist on the left end of the scale (i.e., 1), and by placing those who indicated to vote constitutional, libertarian, or anarcho-capitalist on the right end of the scale (i.e., 7). Including those participants did not alter displayed results. BIC (full model with all interactions and demographics) $=1169$.

\begin{tabular}{|c|c|c|c|c|}
\hline & Coefficient & Standard error & Wald statistic & $p$ \\
\hline Intercept & -0.13 & 0.07 & -1.88 & 0.06 \\
\hline Frame received & 0.23 & 0.10 & 2.34 & 0.02 \\
\hline Political affiliation & -0.16 & 0.05 & -3.20 & $<0.01$ \\
\hline Environmental values (NEP) & 0.17 & 0.05 & 3.47 & $<0.01$ \\
\hline Numeracy & -0.31 & 0.07 & -4.20 & $<0.01$ \\
\hline Frame received $\times$ numeracy & 0.15 & 0.10 & 1.55 & 0.12 \\
\hline Political affiliation $\times$ NEP & -0.01 & 0.05 & -0.19 & $>0.25$ \\
\hline Political affiliation $\times$ numeracy & -0.04 & 0.05 & -0.70 & $>0.25$ \\
\hline $\mathrm{NEP} \times$ numeracy & 0.10 & 0.05 & 2.05 & 0.04 \\
\hline Political affiliation $\times$ NEP $\times$ numeracy & 0.04 & 0.04 & 0.99 & $>0.25$ \\
\hline
\end{tabular}

a. Loss of income and delayed economic development

b. Contamination and disease from flood and sewer water

c. Direct damage to property, infrastructure and utilities

d. Loss of life and personal injury

(a) Study 1: Communicators

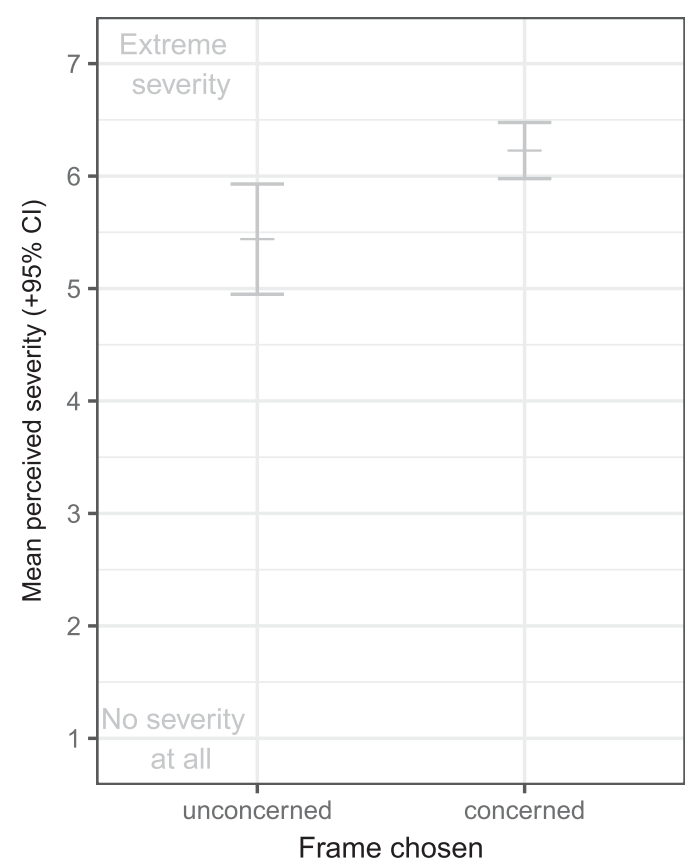

\section{[LISTENERS]}

Please read the following information carefully before moving on to the questions.

When thinking about what climate change means for people, one question is how it will affect towns and cities. Governments, businesses, individuals, and other groups can

(b) Study 2: listeners

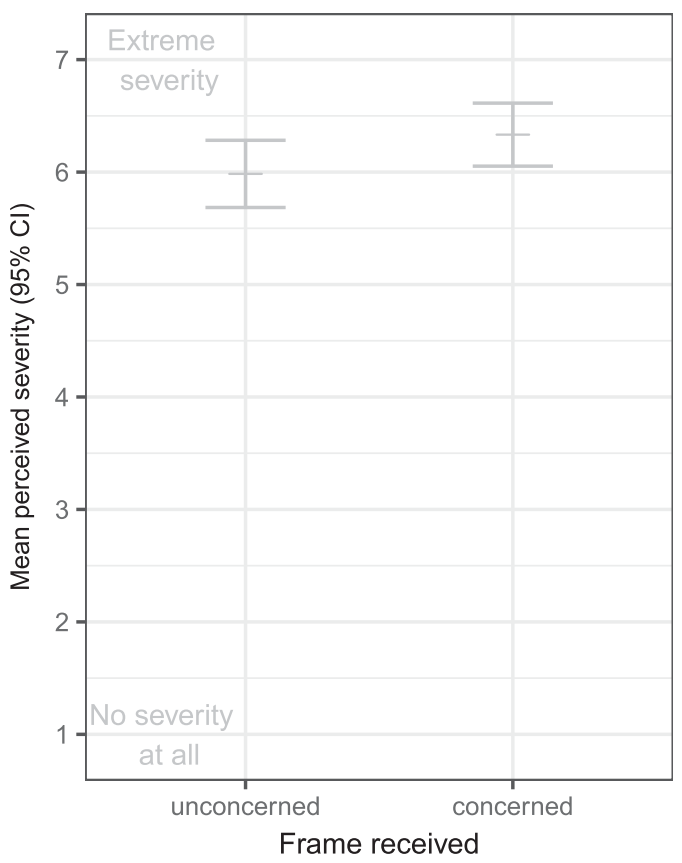

FIG. F1. Mean perceived severity of consequences of precipitation change ( $+95 \%$ confidence interval) by (a) communicators choosing a verbal frame for communicating an uncertain climate projection in pilot study 1 and (b) listeners receiving different verbal frames for the uncertain projection in pilot study 2 . In the pilot studies, mean perceived severity of consequences following precipitation change was measured with a four-item scale, ranging from 1 ("No severity at all") to 7 ("Extreme severity") (see Table 1). We included the fifth item measuring overall perceived severity into the main studies in order to reduce ceiling effects observed here. 
TABLE G1. Perceived severity of listeners in main study 1 by levels of environmental values, political affiliation, and levels of numeracy. For the purpose of this display, participants' average value on the NEP scale and continuous answers on the political affiliation scale were binarized using a median split.

\begin{tabular}{|c|c|c|c|}
\hline Levels of numeracy & NEP & Political affiliation & Mean perceived severity (SE) \\
\hline \multirow[t]{4}{*}{1} & Low & Republican & $5.60(-)$ \\
\hline & & Democrat & $5.05(1.08)$ \\
\hline & High & Republican & $4.43(0.13)$ \\
\hline & & Democrat & $5.0(0.12)$ \\
\hline \multirow[t]{4}{*}{2} & Low & Republican & - \\
\hline & & Democrat & $3.80(0)$ \\
\hline & High & Republican & $4.35(0.21)$ \\
\hline & & Democrat & $4.88(0.15)$ \\
\hline \multirow[t]{4}{*}{3} & Low & Republican & - \\
\hline & & Democrat & $5.10(0.10)$ \\
\hline & High & Republican & $3.92(0.27)$ \\
\hline & & Democrat & $4.59(0.18)$ \\
\hline \multirow[t]{4}{*}{4} & Low & Republican & $4.27(1.18)$ \\
\hline & & Democrat & $5.0(-)$ \\
\hline & High & Republican & $3.90(0.18)$ \\
\hline & & Democrat & $4.68(0.12)$ \\
\hline
\end{tabular}

use this information to devise plans for the future development of their community. For example, if severe hurricanes are likely to occur more frequently near a particular coastal city, that community might prepare by building better levees, improving its evacuation plan, and so on.

In Great Britain, some are concerned that climate change will lead to more winter precipitation. Heavier and more frequent winter rainfall events could lead to flooding, which could result in injuries and fatalities, damage to property and infrastructure, disease spread, delayed economic development, and other consequences.

In 2010, London's mayor consulted the elected London Assembly on the issue of climate change. Imagine that one assembly member, summarizing evidence from a reputable source, stated:

\section{[Concerned verbal frame]}

1. "By the 2050s, annual winter precipitation in Greater London could have increased by as much as $33 \%$."

\section{[Unconcerned verbal frame]}

"By the 2050s, annual winter precipitation in Greater London is very unlikely to have increased by more than $33 \%$."

\section{[Measures-LISTENERS]}

If increased flood risk were judged to be of significant concern, it might influence the design and updating of infrastructure, the construction of new buildings, the development of emergency response plans, and so on.

Please answer the following questions using the assembly member's statement and data alone. There is no right answer-your gut instinct is what matters to us.

TABLE H1. Media quotations, illustrating the use of different verbal frames for summarizing uncertain numerical climate projections.

\begin{tabular}{|c|c|}
\hline Media quote & Reference \\
\hline $\begin{array}{l}\text { "Study finds top fossil fuel producers' emissions } \\
\text { responsible for as much as half of global surface } \\
\text { temperature increase (...)" }\end{array}$ & $\begin{array}{l}\text { https://www.ucsusa.org/press/2017/study-finds-top-fossil-fuel- } \\
\text { producers-emissions-responsible-much-half-global-surface\#.WvH_Ly- } \\
\text { B3OQ; accessed on } 17 \text { May } 2018\end{array}$ \\
\hline $\begin{array}{l}\text { "Researchers expected to find a } 6 \text { percent increase in Hurricane } \\
\text { Harvey rainfall totals, but instead found that climate } \\
\text { change increased those totals by at least } 19 \text { percent and } \\
\text { as much as } 38 \text { percent." }\end{array}$ & $\begin{array}{l}\text { https://www.scientificamerican.com/article/global-warming-tied-to- } \\
\text { hurricane-harvey/ }\end{array}$ \\
\hline $\begin{array}{l}\text { "According to an IPCC report, if greenhouse gas emissions } \\
\text { remain unchecked, global sea levels could rise by as much } \\
\text { as } 3 \text { feet ( } 0.9 \text { meters) by } 2100 . "\end{array}$ & https://www.livescience.com/37057-global-warming-effects.html \\
\hline $\begin{array}{l}\text { "It now rains considerably more in winter almost everywhere } \\
\text { in Germany; in some cases, precipitation volumes have } \\
\text { increased by as much as } 30 \text { percent in the cold season. In } \\
\text { contrast, summers in many Federal States have become dryer." }\end{array}$ & $\begin{array}{l}\text { https://www.climaterealityproject.org/blog/how-climate-change- } \\
\text { affecting-germany }\end{array}$ \\
\hline
\end{tabular}


1. What percent change in annual winter precipitation would you expect in Greater London, in comparison with previous decades, in the 2050s? $\%$

2. With what severity do you think London will experience these potential consequences of flooding by the 2050s? (For each, a 7-point scale, ranging from "No severity at all" to "Extreme severity".)

a. Loss of income and delayed economic development

b. Contamination and disease from flood and sewer water

c. Direct damage to property, infrastructure and utilities

d. Loss of life and personal injury

\section{APPENDIX B}

\section{Sample Characteristics of Pilot Study 1 and} Pilot Study 2

Table B1 shows sample characteristics for pilot study 1 (communicators) and pilot study 2 (listeners).

\section{APPENDIX C}

\section{Logistic Regression, Predicting Frame Choice (Concerned vs Unconcerned) in Pilot Study 1 (Communicators)}

Table $\mathrm{C} 1$ shows coefficients from a logistic regression model, predicting frame choices in pilot study 1 .

\section{APPENDIX D}

\section{Dominance Analysis Results for Logistic Regression Predictors in Main and Pilot Study 1}

Table D1 shows dominance analysis results for the main study and pilot study 1 .

\section{APPENDIX E}

\section{Linear Regression, Predicting Perceived Severity of Consequences, Dependent on Verbal Frame} Received, Environmental Values (NEP), Political Affiliation, and Levels of Numeracy in Pilot Study 2 (Listeners)

Table E1 shows coefficients from a linear regression model, predicting perceived severity of consequences in pilot study 2 .

\section{APPENDIX F}

\section{Mean Perceived Severity of Consequences in Study 1 (Communicators) and Study 2 (Listeners) by Verbal Frame}

Figure F1 shows mean perceived severity of consequences in pilot study 1 (communicators) and pilot study 2 (listeners).

\section{APPENDIX G}

\section{Mean Perceived Severity of Listeners in Main Study 1 by Levels of Environmental Values, Political Affiliation, and Numeracy}

Table G1 reports mean values of perceived severity by levels of numeracy, environmental values (median split), and political affiliation (median split).

\section{APPENDIX H}

\section{Exemplary Media Quotations Using Different Verbal Frames Used for Summarizing Numerical Climate Projections}

Table H1 provides examples for media quotations, illustrating the use of different verbal frames for summarizing uncertain numerical climate projections.

\section{REFERENCES}

Azen, R., and N. Traxel, 2009: Using dominance analysis to determine predictor importance in logistic regression. J. Educ. Behav. Stat., 34, 319-347, https://doi.org/10.3102/ 1076998609332754.

Benjamin, D., H. H. Por, and D. Budescu, 2017: Climate change versus global warming: Who is susceptible to the framing of climate change? Environ. Behav., 49, 745-770, https://doi.org/ 10.1177/0013916516664382.

Beyth-Marom, R., 1982: How probable is probable? A numerical translation of verbal probability expressions. J. Forecasting, 1, 257-269, https://doi.org/10.1002/for.3980010305.

Brüggemann, M., and S. Engesser, 2017: Beyond false balance: How interpretive journalism shapes media coverage of climate change. Global Environ. Change, 42, 58-67, https://doi.org/ 10.1016/j.gloenvcha.2016.11.004.

Bruine de Bruin, W., G. Wong-Parodi, and M. G. Morgan, 2014: Public perceptions of local flood risk and the role of climate change. Environ. Syst. Decis., 34, 591-599, https://doi.org/ 10.1007/s10669-014-9513-6.

Budescu, D. V., 1993: Dominance analysis: A new approach to the problem of relative importance of predictors in multiple regression. Psychol. Bull., 114, 542-551, https://doi.org/10.1037/ 0033-2909.114.3.542.

, T. M. Karelitz, and T. Wallsten, 2003: Predicting the directionality of probability phrases from their membership functions. J. Behav. Decis. Making, 16, 159-180, https:// doi.org/10.1002/bdm.440. 
— H.-H. Por, and S. B. Broomell, 2012: Effective communication of uncertainty in the IPCC reports. Climatic Change, 113, 181-200, https://doi.org/10.1007/s10584-011-0330-3.

—,$- \ldots$, and M. Smithson, 2014: The interpretation of IPCC probabilistic statements around the world. Nat. Climate Change, 4, 508-512, https://doi.org/10.1038/nclimate2194.

Cacciatore, M. A., D. A. Scheufele, and S. Iyengar, 2016: The end of framing as we know it ... and the future of media effects. Mass Commun. Soc., 19, 7-23, https://doi.org/10.1080/ 15205436.2015.1068811.

Carmichael, J. T., R. J. Brulle, and J. K. Huxster, 2017: The great divide: Understanding the role of media and other drivers of the partisan divide in public concern over climate change in the USA, 2001-2014. Climatic Change, 141, 599-612, https:// doi.org/10.1007/s10584-017-1908-1.

Chong, D., and J. N. Druckman, 2007: Framing theory. Annu. Rev. Polit. Sci., 10, 103-126, https://doi.org/10.1146/annurev. polisci.10.072805.103054.

Clarke, D., 2012: How will climate change affect food production? The Guardian, 19 September, https://www.theguardian.com/ environment/2012/sep/19/climate-change-affect-food-production.

Cohen, J., 1988: Statistical Power Analysis for the Behavioral Sciences. 2nd ed. Lawrence Erlbaum, 567 pp.

Cokely, E., M. Galesic, E. Schulz, S. Ghazal, and R. GarciaRetamero, 2012: Measuring risk literacy: The Berlin Numeracy Test. Judgment Decis. Making, 7, 25-47, http:// journal.sjdm.org/11/11808/jdm11808.pdf.

Corner, A., E. Markowitz, and N. Pidgeon, 2014: Public engagement with climate change: The role of human values. Wiley Interdiscip. Rev.: Climate Change, 5, 411-422, https://doi.org/ 10.1002/wcc.269.

Dunlap, R. E., K. D. Van Liere, A. G. Mertig, and R. E. Jones, 2000: Measuring endorsement of the New Ecological Paradigm: A revised NEP scale. J. Soc. Issues, 56, 425-442, https:// doi.org/10.1111/0022-4537.00176.

, A. M. McCright, and J. H. Yarosh, 2016: The political divide on climate change: Partisan polarization widens in the U.S. Environ. Sci. Policy Sustain. Dev., 58, 4-23, https://doi.org/ 10.1080/00139157.2016.1208995.

Erev, I., and B. L. Cohen, 1990: Verbal versus numerical probabilities: Efficiency, biases, and the preference paradox. Organ. Behav. Hum. Decis. Processes, 45, 1-18, https://doi.org/10.1016/ 0749-5978(90)90002-Q.

Galesic, M., A. Kause, and W. Gaissmaier, 2016: A sampling framework for uncertainty in individual environmental decisions. Top. Cogn. Sci., 8, 242-258, https://doi.org/10.1111/ tops. 12172.

Garcia-Retamero, R., and E. T. Cokely, 2014: The influence of skills, message frame, and visual aids on prevention of sexually transmitted diseases. J. Behav. Decis. Making, 27, 179-189, https://doi.org/10.1002/bdm.1797.

Greater London Authority, 2010: The Draft Climate Change Adaptation Strategy for London. Greater London Authority, 136 pp., https://www.preventionweb.net/go/13313.

Harold, J., I. Lorenzoni, K. R. Coventry, and A. Minns, 2017: Enhancing the accessibility of climate change data visuals: Recommendations to the IPCC and guidance for researchers. Nat. Climate Change, 6, 1080-1089, https://doi.org/10.1038/nclimate3162.

Hart, P. S., 2013: The role of numeracy in moderating the influence of statistics in climate change messages. Public Understanding Sci., 22, 785-798, https://doi.org/10.1177/0963662513482268.

—_, and E. C. Nisbet, 2012: Boomerang effects in science communication: How motivated reasoning and identity cues
Amplify opinion polarization about climate mitigation policies. Commun. Res., 39, 701-723, https://doi.org/10.1177/ 0093650211416646.

,-- , and T. A. Myers, 2015: Public attention to science and political news and support for climate change mitigation. Nat. Climate Change, 5, 541-545, https://doi.org/10.1038/ nclimate2577.

Hohle, S., and K. H. Teigen, 2018: More than $50 \%$ or less than $70 \%$ chance: Pragmatic implications of single bound probability estimates. J. Behav. Decis. Making, 31, 138-150, https:// doi.org/10.1002/bdm.2052.

Hornsey, M. J., E. A. Harris, P. G. Bain, and K. S. Fielding, 2016: Meta-analyses of the determinants and outcomes of belief in climate change. Nat. Climate Change, 6, 622-626, https:// doi.org/10.1038/nclimate2943.

IPCC, 2014: Climate Change 2014: Mitigation of Climate Change. O. Edenhofer et al., Eds., Cambridge University Press, 1465 pp., https://www.ipcc.ch/report/ar5/wg3/.

Joslyn, S., L. Nemec, and S. Savelli, 2013: The benefits and challenges of predictive interval forecasts and verification graphics for end users. Wea. Climate Soc., 5, 133-147, https://doi.org/ 10.1175/WCAS-D-12-00007.1.

Juanchich, M., M. Sirota, and C. L. Butler, 2012: The perceived functions of linguistic risk quantifiers and their effect on risk, negativity perception and decision making. Organ. Behav. Hum. Decis. Processes, 118, 72-81, https://doi.org/10.1016/ j.obhdp.2012.01.002.

Kahan, D. M., E. Peters, M. Wittlin, P. Slovic, L. L. Ouellette, D. Braman, and G. Mandel, 2012: The polarizing impact of science literacy and numeracy on perceived climate change risks. Nat. Climate Change, 2, 732-735, https://doi.org/10.1038/ nclimate1547.

LeBreton, J., S. Tonidandel, and D. V. Krasikova, 2013: Residualized relative importance analysis. A technique for the comprehensive decomposition of variance in higher order regression models. Organ. Res. Methods, 16, 449-473, https:// doi.org/10.1177/1094428113481065.

Malka, A., J. A. Krosnick, and G. Langer, 2009: The association of knowledge with concern about global warming: Trusted information sources shape public thinking. Risk Anal., 29, 633-647, https://doi.org/10.1111/j.1539-6924.2009.01220.x.

Mandel, D. R., 2014: Do framing effects reveal irrational choice? J. Exp. Psychol. Gen., 143, 1185-1198, https://doi.org/10.1037/ a0034207.

Marteau, T. M., 1989: Framing of information: Its influence upon decisions of doctors and patients. Br. J. Soc. Psychol., 28, 8994, https://doi.org/10.1111/j.2044-8309.1989.tb00849.x.

McCright, A. M., M. Charters, K. Dentzman, and T. Dietz, 2016: Examining the effectiveness of climate change frames in the face of a climate change denial counter-frame. Top. Cogn. Sci., 8, 76-97, https://doi.org/10.1111/tops.12171.

McDonald, R. I., H. Y. Chai, and B. R. Newell, 2015: Personal experience and the "psychological distance" of climate change: An integrative review. J. Environ. Psychol., 44, 109-118, https:// doi.org/10.1016/j.jenvp.2015.10.003.

McKenzie, C. R. M., and J. D. Nelson, 2003: What a speaker's choice of frame reveals: Reference points, frame selection, and framing effects. Psychon. Bull. Rev., 10, 596-602, https:// doi.org/10.3758/BF03196520.

McNeil, B. J., S. G. Pauker, H. C. Sox, and A. Tversky, 1982: On the elicitation of preferences for alternative therapies. N. Engl. J. Med., 306, 1259-1262, https://doi.org/10.1056/ NEJM198205273062103. 
Morton, T. A., A. Rabinovich, D. Marshall, and P. Bretschneider, 2011: The future that may (or may not) come: How framing changes responses to uncertainty in climate change communications. Global Environ. Change, 21, 103-109, https://doi.org/10.1016/ j.gloenvcha.2010.09.013.

Mossler, M. V., A. Bostrom, R. P. Kelly, K. M. Crosman, and P. Moy, 2017: How does framing affect policy support for emissions mitigation? Testing the effects of ocean acidification and other carbon emissions frames. Global Environ. Change, 45, 63-78, https://doi.org/10.1016/j.gloenvcha.2017.04.002.

Moussaïd, M., H. Brighton, and W. Gaissmaier, 2015: The amplification of risk in experimental diffusion chains. Proc. Natl. Acad. Sci. USA, 112, 5631-5636, https://doi.org/10.1073/ pnas. 1421883112.

Murphy, J., and Coauthors, 2010: UK Climate Projections Science Report: Climate change projections. Met Office Hadley Centre, 192 pp. (see especially 21-35).

Nelson, T. E., Z. M. Oxley, and R. A. Clawson, 1997: Toward a psychology of framing effects. Political Behav., 19, 221-246, https://doi.org/10.1023/A:1024834831093.

Peters, E., D. Västfjäll, P. Slovic, C. K. Mertz, K. Mazzocco, and S. Dickert, 2006: Numeracy and decision making. Psychol. Sci., 17, 407-413, https://doi.org/10.1111/j.1467-9280.2006.01720.x.

Pidgeon, N., and B. Fischhoff, 2011: The role of social and decision sciences in communicating uncertain climate risks. Nat. Climate Change, 1, 35-41, https://doi.org/10.1038/nclimate1080.

Poortinga, W., A. Spence, L. Whitmarsh, S. Capstick, and N. F. Pidgeon, 2011: Uncertain climate: An investigation into public scepticism about anthropogenic climate change. Global Environ. Change, 21, 1015-1024, https://doi.org/10.1016/j.gloenvcha.2011.03.001.

Scannell, L., and R. Gifford, 2013: Personally relevant climate change. Environ. Behav., 45, 60-85, https://doi.org/10.1177/ 0013916511421196.

Scheufele, D. A., 2014: Science communication as political communication. Proc. Natl. Acad. Sci. USA, 111, 13 585-13 592, https://doi.org/10.1073/pnas.1317516111.

- , and S. Iyengar, 2014: The state of framing research. The Oxford Handbook of Political Communication, K. Kenski and
K. Hall Jamieson, Eds., Oxford University Press, https://doi.org/ 10.1093/oxfordhb/9780199793471.013.47.

Sher, S., and C. R. M. McKenzie, 2006: Information leakage from logically equivalent frames. Cognition, 101, 467-494, https:// doi.org/10.1016/j.cognition.2005.11.001.

Smithson, M., D. V. Budescu, S. B. Broomell, and H.-H. Por, 2012: Never say "not": Impact of negative wording in probability phrases on imprecise probability judgments. Int. J. Approx. Reason., 53, 1262-1270, https://doi.org/10.1016/j.ijar.2012.06.019.

Spence, A., and N. Pidgeon, 2010: Framing and communicating climate change: The effects of distance and outcome frame manipulations. Global Environ. Change, 20, 656-667, https:// doi.org/10.1016/j.gloenvcha.2010.07.002.

Stephens, E. M., T. L. Edwards, and D. Demeritt, 2012: Communicating probabilistic information from climate model ensembles: Lessons from numerical weather prediction. Wiley Interdiscip. Rev.: Climate Change, 3, 409-426, https:// doi.org/10.1002/wcc.187.

Teigen, K. H., 2008: More than $X$ is a lot: Pragmatic implicatures of one-sided uncertainty intervals. Soc. Cogn., 26, 379-400, https://doi.org/10.1521/soco.2008.26.4.379.

— A. Halberg, and K. I. Fostervold, 2007: Single-limit interval estimates as reference points. Appl. Cogn. Psychol., 21, 383406, https://doi.org/10.1002/acp.1283.

Tversky, A., and D. Kahneman, 1981: The framing of decisions and the psychology of choice. Science, 211, 453-458, https:// doi.org/10.1126/science.7455683.

Visschers, V. H. M., R. M. Meertens, W. W. F. Passchier, and N. N. K. De Vries, 2009: Probability information in risk communication: A review of the research literature. Risk Anal., 29, 267-287, https://doi.org/10.1111/j.1539-6924.2008.01137.x.

Whitmarsh, L., 2011: Scepticism and uncertainty about climate change: Dimensions, determinants and change over time. Global Environ. Change, 21, 690-700, https://doi.org/10.1016/ j.gloenvcha.2011.01.016.

Wilson, D. K., R. M. Kaplan, and L. J. Schneiderman, 1987: Framing of decisions and selections of alternatives in health care. Soc. Behav., 2, 51-59. 